\title{
Photoperiodic responses of Sahelian malaria mosquitoes Anopheles coluzzii and An. arabiensis
}

\author{
Diana L. Huestis ${ }^{1}$, Monica L. Artis ${ }^{1}$, Peter A. Armbruster ${ }^{2}$ and Tovi Lehmann ${ }^{1 *}(\mathbb{D}$
}

\begin{abstract}
Background: Throughout large parts of sub-Saharan Africa, seasonal malaria transmission follows mosquito density, approaching zero during the dry season and peaking during the wet season. The mechanisms by which malaria mosquitoes survive the long dry season, when no larval sites are available remain largely unknown, despite being long recognized as a critical target for vector control. Previous work in the West African Sahel has led to the hypothesis that Anopheles coluzzii (formerly M-form Anopheles gambiae) undergoes aestivation (dry-season diapause), while Anopheles gambiae (s.s.) (formerly S-form An. gambiae) and Anopheles arabiensis repopulate each wet season via long-distance migration. The environmental cues used by these species to signal the oncoming dry season have not been determined; however, studies, mostly addressing mosquitoes from temperate zones, have highlighted photoperiod and temperature as the most common token stimuli for diapause initiation. We subjected newly established colonies of An. coluzzii and An. arabiensis from the Sahel to changes in photoperiod to assess and compare their responses in terms of longevity and other relevant phenotypes.
\end{abstract}

Results: Our results showed that short photoperiod alone and to a lesser extent, lower nightly temperature (representing the early dry season), significantly increased longevity of $A$. coluzzii (by $~ 30 \%, P<0.001$ ) but not of An. arabiensis. Further, dry season conditions increased body size but not relative lipid content of $A n$. coluzzii, whereas body size of An. arabiensis decreased under these conditions.

Conclusions: These species-specific responses underscore the capacity of tropical anophelines to detect mild changes $(\sim 1 \mathrm{~h})$ in photoperiod and thus support the role of photoperiod as a token stimulus for $A n$. coluzzii in induction of aestivation, although, these responses fall short of a complete recapitulation of aestivation under laboratory conditions.

Keywords: Anopheles coluzzii, Anopheles gambiae (s.l.), Anopheles arabiensis, African malaria mosquito, Dormancy, Diapause, Aestivation, Survival, Longevity, Body size, Dry season, Life history, Seasonality

\section{Background}

Although many strides have been made in recent years, malaria remains a global challenge, with hundreds of millions of cases, near 450,000 deaths, and billions of dollars of lost productivity each year [1] mostly in sub-Saharan Africa. Mosquitoes in the genus Anopheles are the primary vectors of human malaria, yet much about their basic ecology still

\footnotetext{
* Correspondence: tlehmann@niaid.nih.gov

'Laboratory of Malaria and Vector Research, National Institute of Allergy and

Infectious Diseases, National Institutes of Health, Rockville, MD, USA

Full list of author information is available at the end of the article
}

remains unknown. Anopheles gambiae, An. coluzzii and An. arabiensis are widespread across the African continent, inhabiting a wide range of habitats with environmental conditions that vary both spatially and temporally [2-5]. Specifically, rainfall amount and distribution is highly variable across their range, with large portions having a 4-7 months-long dry season [6-10]. Because anopheline mosquitoes have a relatively short lifespan, estimated at 2-5 weeks; [11-15] and the aquatic stages tolerate desiccation only for a few days $[16,17]$, the mechanism(s) underlying their persistence without surface water in extensive regions 
with dry spells exceeding 4 months is one of the longest unanswered questions in medical entomology $[6,18-22]$. Two competing hypotheses have been proposed to explain the persistence of Anophelines in regions with extended dry seasons: (i) long-distance migration (LDM) from areas with permanent larval sites to seasonally arid areas after the rainy season begins or (ii) extension of life in local populations via aestivation, (summer diapause) while hidden in local shelters [6, 19-23]. Knowledge of the mechanism(s) of persistence used by each vector species could yield effective intervention strategies for reducing malaria transmission across vast areas with seasonal cycles.

In the Sahel (latitudes $12-18^{\circ}$ ), it is hypothesized that An. coluzzii (previously M-form An. gambiae; [24]) survive the dry season by aestivating locally, while $A n$. gambiae (previously the S-form) and $A n$. arabiensis persist via annual long-distance migration [8, 20, 25-28]. The physiological mechanisms of mosquito aestivation and its initiation and maintenance in the field have been studied in recent years, yet are still largely unknown $[21,29-34]$. However, if aestivation is similar to other cases of insect diapause, it may be initiated by predictable, seasonal shifts in photoperiod, temperature, or other environmental conditions [35-45]. In the Sahel, rainfall sustaining surface waters for mosquito breeding only occurs between June and October. The maximal photoperiod change between seasons is $\sim 2 \mathrm{~h}$ and during the supposed transition period (late October), inferred based on the species-specific disappearance of $A n$. coluzzii [8], the photophase is only $15-20 \mathrm{~min}$ shorter than the scotophase (11.75:12.15 h, L:D, respectively). During that time, the daily rate of decrease in photoperiod is the highest (45 s/day) and both $\mathrm{RH}$ and nightly temperatures start falling [21, 33]. Seasonal shifts in photoperiod are typically associated with temperate climates, yet insects and other organisms are sensitive to even subtle shifts in photoperiod which occur in the tropics $[45,46]$. For example, at latitude $9^{\circ}$, the beetle Stenotarsus rotundus responds to photoperiod by degeneration or development of flight muscles [47], the African stonechat at the equator probably uses subtle differences in the time of sunrise and sunset [48], and the spotted antbird detects changes in photoperiod as slight as $20 \mathrm{~min}$ and responds in dramatic changes in reproduction [49]. Additionally, a combination of shorter day length and lower temperatures, typical of the dry season were key to induction of aestivation in the Sahelian bruchid beetles, in which the adults seek (unknown) shelters during the long dry season [50, 51]. Thus, it is reasonable that photoperiod, including the daily change in photoperiod, possibly coupled with temperature change, could be the seasonal cue(s) used by mosquitoes to initiate aestivation in the Sahel. Uncovering the factors which stimulate mosquitoes to begin, maintain, and terminate aestivation could lead to better prediction of disease-transmission seasons and may also provide novel opportunities for vector control [21, 34, 52].

To test if $A n$. coluzzii mosquitoes use photoperiod and temperature as cues to initiate and/or maintain aestivation, we measured changes in their longevity and other relevant life-history traits under dry-season as compared to wet-season photoperiod and temperature conditions. The present study extends previous results showing that under short photoperiod, An. gambiae (G3 colony) had larger body size and larger amount of cuticular hydrocarbons standardized for body size [34]. Here, we included the presumably non-aestivating West-African An. arabiensis as a control comparison based on the rationale that $A n$. arabiensis would not increase its longevity in response to the change in photoperiod. The strategy used by of $A n$. arabiensis to persist through the dry season is less clear; however, evidence from Mali suggests that persistence in this population relies on long-distance migration during the rainy season and therefore it is not expected to respond to such changes or its response would not agree with that of An. coluzzii [6-8, 19-21, 28, 32]. In addition to longevity, we predicted that other aestivation-relevant phenotypes, such as body-size and nutritional reserves would be affected by changes in photoperiod in $A n$. coluzzii but not in $A n$. arabiensis (Table 1). These hypotheses regarding the expected change in response to photoperiod and temperature range in strength from the strongest which is for adult longevity [20], through the moderately-strong predicted change in body size [29, 30, 34] based on the larger body size of $A n$. coluzzii mosquitoes in the dry season, to weaker predictions about body mass and developmental time, which have not been assessed previously. A larger body size is expected to confer higher tolerance to desiccation due to smaller surface/volume [29]. To test these hypotheses, new laboratory colonies of these species were established from a Sahelian field site. Photoperiod conditions were selected to mirror those which naturally occur at that source location during the wet season (June-July), the transition period between the wet and the dry season (OctoberNovember), and during the dry season (January-February). Our results revealed that An. coluzzii responded to the changes in photoperiod more than its sibling species $A n$. arabiensis. An. coluzzii expressed changes in development time, body size (and body mass) at emergence, as well as in longevity. 
The responses agree with predictions based on evidence of aestivation in the dry season, but they were modest in size, suggesting that additional conditions may be critical for full expression of aestivation.

\section{Methods}

\section{Mosquito colonies}

New laboratory colonies of An. coluzzii and An. arabiensis were established in November 2012 from blood-fed and gravid females collected in the village of Thierola, Mali, where previous studies on the dry-season ecology of these mosquitoes have been conducted since 2008 [ 8 , 20]. Wild females that laid eggs and two of their offspring were identified to species using the PCR followed by HhaI digestion as previously described [53]. Species identity were checked and confirmed at generations 1,2 and 4. Mosquitoes of each species were maintained for 4 generations prior to the start of the first experiment to increase abundance and reduce environmental and maternal effects from the field. Mosquitoes were kept under 12:12 L:D cycle, $27^{\circ} \mathrm{C}$, and $75 \% \mathrm{RH}$. Larvae were maintained in pans containing $\sim 2.5 \mathrm{~cm}$ of dechlorinated water and fed daily grounded fish food TetraMin Baby fish food (Spectrum Brands, Inc., Madison, WI, USA). Adults were provided with $10 \%$ Karo syrup that was refreshed daily. When the mosquitoes were 5 days old, they were offered blood meal on a human arm (generation 1 and 2) and thereafter on mice. Mosquitoes were allowed to feed for $15 \mathrm{~min}$ and were given an additional $5 \mathrm{~min}$ if the feeding rate was $<50 \%$.

\section{Experimental design}

In the first experiment, hereafter referred to as "photoperiod alone" or "Exp. 1", we used custom-built photoperiod chambers described previously [42] to simulate the daily photoperiod and daily changes in photoperiod which occur in our field area. Each photoperiod chamber was equipped with full-spectrum fluorescent bulbs and controlled by ChronTrol XT-4 timers (ChronTrol Corp., San Diego, CA, USA). We simulated 3 light regimes characteristic of different seasonal periods. First, the early wet season photoperiod (July through August), was simulated with an initial 13:11 (L:D) that decreased by $10 \mathrm{~s} / \mathrm{d}$. Second, the photoperiod during the transition between the wet and the dry seasons (October through November, when An. coluzzii numbers fall rapidly, as presumably they move to shelters for aestivation; $[8,25]$ ) was simulated with an initial 12:12 (L:D) that decreased by $45 \mathrm{~s} / \mathrm{d}$ for 40 days, after which the rate of decrease was decreased by $2 \mathrm{~s} / \mathrm{d}$ every 2 days until the rate was $10 \mathrm{~s} / \mathrm{d}$. Finally, the early dry season photoperiod (January through February) was simulated with an initial 11:13 (L:D) that increased by $10 \mathrm{~s} / \mathrm{d}$. Photoperiod treatments were designed based on calculated day-length (and its daily shift) for the latitude and longitude of Thierola, Mali $\left(13.659^{\circ} \mathrm{N}, 7.215^{\circ} \mathrm{W}\right)$, using a freely available sunrise- and sunset-calculating resource which measures day length to the second (https://arachnoid.com/lutusp/ sunrise/).

After the colonies had been expanded for 4 generations (above), cages of 6-9 day-old adult mosquitoes ( 400 mosquitoes/cage; 2 cages/species) were fed for $30 \mathrm{~min}$ on an anesthetized Swiss-Webster mouse, with feeding repeated 2 days later to generate large egg batches. Egg dishes (moistened filter paper shaped into a funnel and placed in a paper cup) were placed into the cages 3 days after the second feeding and females were allowed to oviposit overnight. These eggs were counted and randomly divided into 6 batches of 400-600 eggs per species. These 6 batches were randomly assigned to one of three photoperiod treatments: wet season, wet-dry transition, or dry season; each treatment therefore had two replicates per species. Egg batches were flooded with water in small plastic pans within the photoperiod chambers and larvae were reared to pupation. Pupae were removed daily into a new container and newly emerged adults collected and counted each day before being placed into a larger, replicatespecific adult cage. Pupal collection continued for each replicate until at least $95 \%$ had emerged. Adults were provided continuous access to cotton balls soaked in $10 \%$ Karo syrup, which were replaced daily, following observations that some plants (e.g. Acacia spp. and Azadirachta indica) flower during the dry season. Larval pans and adult cages were randomly rearranged daily within each photoperiod chamber to minimize positional effects.

To assess if there were any differences in body size or lipid content between the treatments, 6 newly emerged females were collected on the 4th day of emergence for each group (the peak of the emergence curve) and preserved via immediate desiccation over silica gel. For each individual, wings were mounted and wing-length measured as previously described [54], desiccated carcasses weighed to the nearest $0.001 \mathrm{mg}$ using a Cahn C-31 electrobalance (Cahn Instruments, Cerritos, CA, USA), and total lipid content was quantified using the vanillinphosphoric acid method of Van Handel [55].

Mosquitoes were provided with an anesthetized SwissWebster mouse for blood-feeding on the 8th day after the peak emergence date and on day 10 . Water for oviposition (see above) was provided for all cages 4 days after the second feeding. After the first gonotrophic cycle, all cages were provided identical access to bloodfeeding (once per week for $10 \mathrm{~min}$ ), but only the wetseason photoperiod treatment groups were given access to oviposition water, to better simulate conditions found during the dry-season and the transition from wet 
Table 1 Predicted and observed responses of females Anopheles coluzzii and An. arabiensis to simulated dry season as opposed to wet season conditions in Experiment 1 (photoperiod alone) and Experiment 2 (photoperiod and temperature)

\begin{tabular}{|c|c|c|c|c|c|c|}
\hline \multirow[t]{3}{*}{ Trait } & \multicolumn{2}{|c|}{ Predicted: dry vs wet conditions } & \multicolumn{4}{|c|}{ Observed: dry vs wet conditions } \\
\hline & \multirow[t]{2}{*}{ An. coluzzii } & \multirow[t]{2}{*}{ An. arabiensis } & \multicolumn{2}{|l|}{ An. coluzzii } & \multicolumn{2}{|l|}{ An. arabiensis } \\
\hline & & & Experiment 1 & Experiment 2 & Experiment 1 & Experiment 2 \\
\hline Longevity (Adult) & Change: increase & No change & Increased $\sqrt{ }$ & Increased $\sqrt{ }$ & Not changed $\sqrt{ }$ & Not changed $^{*} \sqrt{ }$ \\
\hline Body Size (WL) & Change: increase & No change & Increased $\sqrt{ }$ & Increased $^{*} \sqrt{ }$ & Decreased $\sqrt{ }$ & Decreased $\sqrt{ }$ \\
\hline Body mass (dry) & Change: increase & No change & Increased $\sqrt{ }$ & Increased $^{*} \sqrt{ }$ & Decreased $\sqrt{ }$ & Decreased $\sqrt{ }$ \\
\hline Lipid content & Change: increase & No change & Not changed & Increased $\sqrt{ }$ & Not changed $\sqrt{ }$ & Not changed $\sqrt{ }$ \\
\hline Larval development Time & Change: increase & No change & Decreased & Not changed & Increased & Not changed $\sqrt{ }$ \\
\hline
\end{tabular}

Notes: Prediction is bold reflect strongest predictions based on previous studies in the field. Checkmarks identify results of the experiment that are consistent with aestivation in An. coluzzii but not in An. arabiensis. Responses that have partly matched predictions were marked with a "',

season to dry season [20, 25, 32]. To assess mortality, dead mosquitoes from each cage were counted and preserved daily until the cage was empty.

The second experiment, hereafter referred to as "photoperiod and temperature" or "Exp. 2", was conducted as a follow up to evaluate the effect of temperature as an additional cue for the dry season lifehistory changes [40]. This experiment was based on the well-established rationale that photoperiodic cues can be affected by temperature $[45,56]$. The design of this experiment was similar to the photoperiod alone experiment, but we only used the wet-season and dryseason photoperiods, i.e. the transition treatment was dropped, based on the results that experiment (see below), which showed little effect of the wet-to-dry season transition treatment. Photoperiod effects are often evaluated under "unambiguous photoperiod conditions", referring to more extreme regimes than typically experienced by natural populations (see [41] and references therein). To better represent the natural conditions [21, 33], showing lower temperatures and greater daily variation of temperatures in the early to mid-dry season, we included wet-season $\left(27{ }^{\circ} \mathrm{C}\right)$ and dry-season $\left(25{ }^{\circ} \mathrm{C}\right.$ nighttime and $29{ }^{\circ} \mathrm{C}$ daytime with $1.5 \mathrm{~h}$ of transition on each side) temperature treatments, which were crossed with the two remaining photoperiod treatments (wetseason and dry-season) in all combinations. The average daily temperature was equal $\left(27^{\circ} \mathrm{C}\right)$ across the treatments of the dry and wet seasons and $\mathrm{RH}$ was kept at $75 \%$ throughout both experiments. Artificial plastic "shelters" were also placed in one corner of the cage (Additional file 1: Figure S1) for all replicates to provide an opportunity for mosquitoes to seek shelter, as has been proposed to occur during the dry season [25].

\section{Statistical methods}

A measure of mean egg-to-adult developmental time was calculated for each cage as the weighted daily average. The calculated mean emergence date for each cage was then used as the starting date for calculating adult longevity. Lipid content was calculated as the ratio of total lipid $(\mu \mathrm{g})$ to the mosquito dry weight $(\mu \mathrm{g})$. Mortality during the first day following introduction of mosquitoes to the cages was assumed to be a result of handling (accidental death). Survival analysis was performed using Proc Lifetest and Proc Phreg [57], testing relationships between longevity and treatment factors using univariate survival analysis in Proc Lifetest (comparing KaplanMeier survival functions between levels of each factor and employing Wilcoxon tests. Multivariate analysis using the Cox proportional hazard regression (Proc Phreg [57]) was carried out with stratification by experiment. Analysis of variance (ANOVA) was conducted using Proc GLM in SAS to test the effect of treatment on development time, body size, and whole-body lipid content. Significant differences between treatments were evaluated using the REGWQ test, unless the interaction(s) were significant; in which case least square means were used.

\section{Results}

Development time (egg deposition to adult ecolosion) A total of 3481 (1733 females) and 4460 (2245 females) adult mosquitoes emerged in the photoperiod-alone experiment (Exp. 1) and the photoperiod and temperature experiment (Exp. 2), respectively. In both experiments, males developed faster than females (Exp. 1: $F_{(1,3474)}=$ 36.6, Exp. 2: $\left.F_{(1,4450)}=30.8, P<0.01\right)$ in analyses within species across treatments. In both experiments, differences between species, treatments, and species-bytreatment interaction were all significant (Exp. 1: $F>31$, Exp. 2: $F>4.5, P<0.037)$.

\section{Photoperiod only: Experiment 1}

Development time of female An. arabiensis increased by 1.5 days, from $13.0 \mathrm{~d}$ to $14.5 \mathrm{~d}$, with decreasing daylength from the wet to the dry season $\left(F_{(1,775)}=91.4, P<\right.$ 0.001; Fig. 1a). In contrast, female An. coluzzii developing under wet-season conditions had the longest development time (14.2 d) while those developing under the 


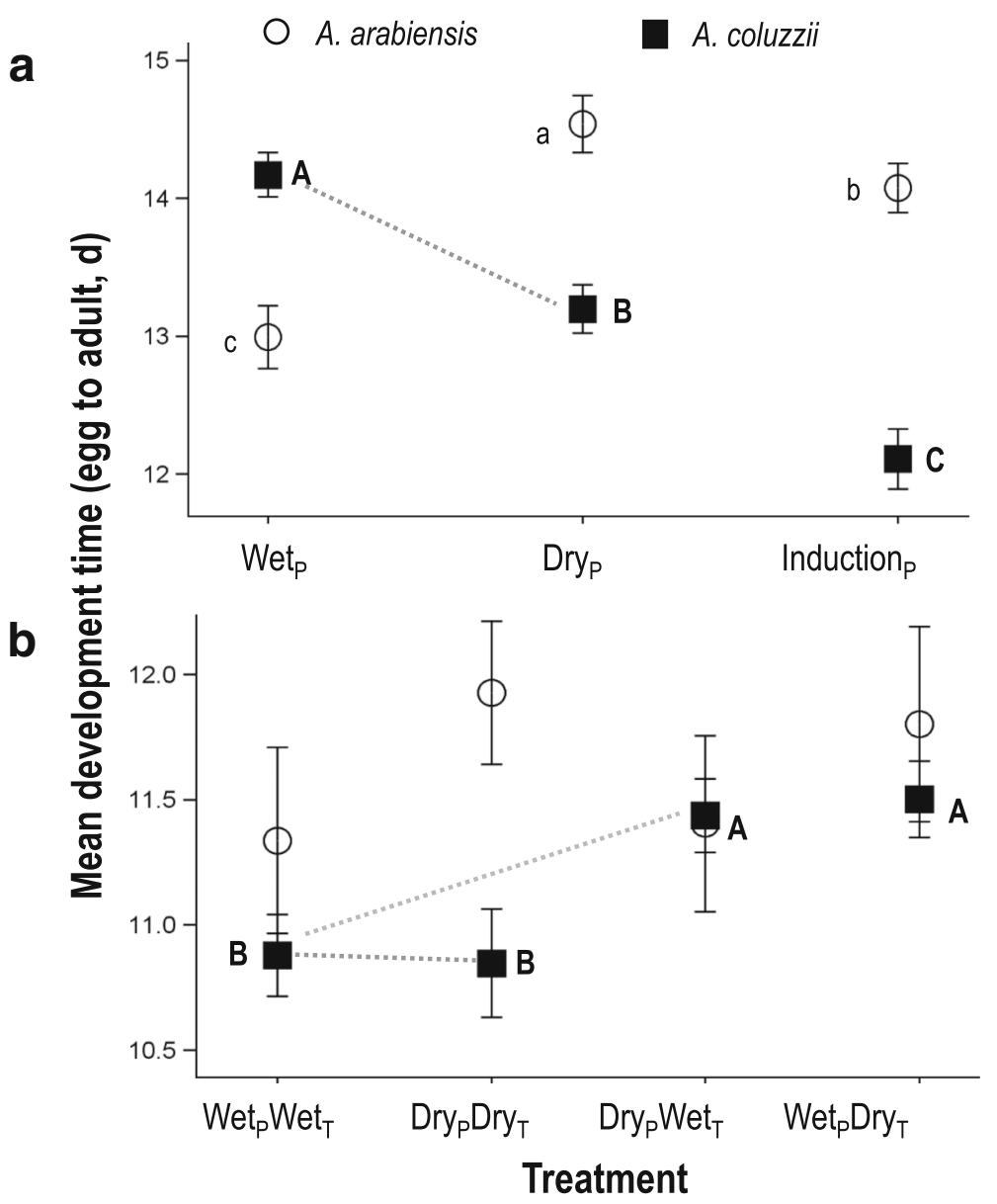

Fig. 1 Mean developmental time for female A. arabiensis (white circles) and A. coluzzii (black squares) under (a) three photoperiod treatments (Experiment 1): wet season, dry season, and wet to dry transition (induction), and (b) four photoperiod-temperature treatment combinations (Experiment 2). The subscript ' $P$ ' and ' $T$ ', denote photoperiod and temperature conditions, respectively. Mean $\pm 2 S E$ are given and significantly different values within each species are designated with letters (REGWQ groupings). The grey dotted line denotes the critical comparison between wet-season and dry-season A. coluzzii in each experiment

induction (wet-to-dry transition) photoperiod had the shortest $\left(12.1 \mathrm{~d}, \quad F_{(1,952)}=66.9, \quad P<0.001 ; \quad\right.$ Fig. $\left.1 \mathrm{a}\right)$, amounting to $15 \%$ reduction in developmental time.

\section{Photoperiod and temperature: Experiment 2}

Development time of female An. arabiensis differed minimally across all 4 photoperiod-temperature combinations $\left(F_{(3,415)}=3.1, \quad P=0.026\right.$; Fig. $\left.1 \mathrm{~b}\right)$ whereas, for female An. coluzzii, the effect of treatment was highly significant $\left(F_{(3,1822)}=16.4, P<0.0001\right)$. However, females developing in the photoperiod-temperature "matched" treatments [i.e. wet-season photoperiod with wet-season temperature $(10.9 \mathrm{~d})$, and dry-season temperature with dry-season photoperiod $(10.8 \mathrm{~d})$ ] were not significantly different from each other $\left(F_{(1,1822)}=0.5, P=0.82\right)$. Moreover, the development time of the two "matched" treatments were significantly shorter $\left(F_{(1,1822)}=47.3, P<\right.$ $0.0001)$ than the two "mismatched" treatments (wet-season photoperiod with dry-season temperature and dry- season photoperiod with wet-season temperature), which were not different from each other $\left(F_{(1,1822)}=0.4, P>\right.$ 0.55; Fig. 1b).

\section{Body size and lipid reserves}

At adult emergence, positive correlations were found between female body size (measured as wing length), dry mass, and lipid mass across species and treatments $(A n$. arabiensis Exp. 1: $0.34<r<0.69,0.002<P<0.15, n=20$ 23; Exp. 2: $0.81<r<0.85, P<0.0001, n=20$; and $A n$. coluzzii Exp. 1: $0.54<r<0.95, P<0.019, n=18-20$; and Exp. 2: $0.56<r<0.64, P<0.0001, n=38)$. However, the relative lipid content (proportion of lipids from total dry mass) was negatively correlated with body size in $A n$. arabiensis (Exp. 1: $-0.58<r<-0.55, P<0.11, n=20-23$; Exp. 2: $-0.69<r<-0.53, P<0.0001, n=20$ ) whilst the correlation was not significantly different from zero in An. coluzzii (Exp. 1: $-0.37<r<-0.36, P<0.12, n=18$; Exp. 2: $-0.16<r<0.29, P<0.085, n=38$ ). These results 
suggest that upon emergence, in An. arabiensis females there is a trade-off between body size and lipid content, whereas in $A n$. coluzzii lipid content is relatively constant across body size.

\section{Experiment 1}

Photoperiod significantly affected female body size (wing length) for both $A n$. arabiensis $\left(F_{(2,22)}=14.3, P=0.0001\right)$ and $A n$. coluzzii $\left(F_{(2,17)}=14.3, P=0.0002\right)$. However, the direction of the change differed between the species; under the dry-season photoperiod, female An. arabiensis were smallest while $A n$. coluzzii were largest (Fig. 2a). Female $A n$. arabiensis were not significantly different in dry mass at emergence between the three photoperiod treatments $\left(F_{(2,22)}=2.8, P=0.085\right)$, although the trend followed that exhibited by their body size (Fig. 2c). In contrast, female An. coluzzii under the dry-season photoperiod had a significantly higher dry mass at emergence than those in either the wet-season or the wet-todry transition treatments $\left(F_{(2,20)}=13.5, \quad P=0.0002\right.$; Fig. 2c). The absolute lipid mass at emergence was not significantly different among treatments for both species $(F<2.38, P>0.12$; Fig. $2 \mathrm{e})$, although the trends are qualitatively similar to those of dry mass. Moreover, relative lipid content was not significantly different between treatments of both species $\left(F_{(2,20)}=3.45, P>0.059\right.$ and $F_{(2,19)}=0.64, P>0.53$ for An. arabiensis and An. coluzzii, respectively; Additional file 1: Figure S2).

\section{Experiment 2}

Temperature $\left(F_{(1,19)}=13.2, P=0.0023\right)$ but not photoperiod alone $\left(F_{(1,19)}=2.3, P=0.15\right)$ or the interaction between photoperiod and temperature $\left(F_{(1,19)}=1.2, P=\right.$ 0.30 ) significantly affected body size (wing length of

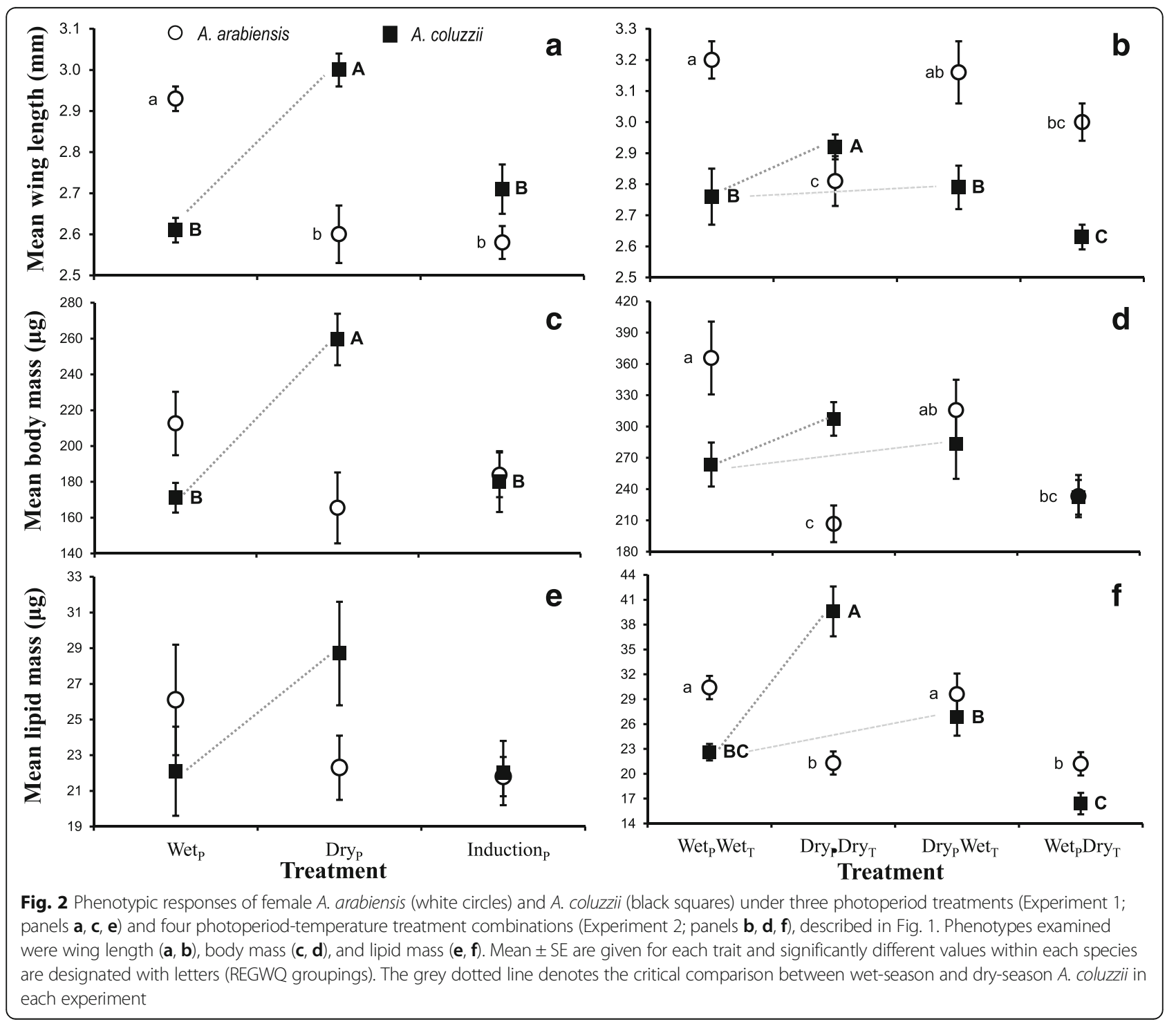


female An. arabiensis. Female An. arabiensis raised under the wet-wet treatment were the largest while those raised under the dry-dry treatment were the smallest (Fig. 2a). In contrast, photoperiod alone $\left(F_{(1,34)}=6.8\right.$, $P<0.014)$ and the interaction between photoperiod and temperature $\left(F_{(1,34)}=4.4, P<0.04\right)$ significantly affected body size (wing length) for female An. coluzzii, while temperature alone was non-significant $\left(F_{(1,34)}=0.0, P=\right.$ 0.96). Similar to the results of Exp. 1, female An. coluzzii raised under the dry-dry treatment were larger than those raised under the wet-wet treatment (Fig. 2b). Temperature $\left(F_{(1,19)}=20.9, P=0.0003\right)$ but not photoperiod $\left(F_{(1,19)}=2.1, P=0.17\right)$ or their interaction $\left(F_{(1,19)}\right.$ $=0.2, P=0.66)$ significantly affected dry mass at emergence for An. arabiensis females. Female An. arabiensis raised under the wet-season temperature treatments were significantly heavier than those females raised under the dry-season temperature treatments (Fig. 2d). For female $A n$. coluzzii, the effect of photoperiod on dry mass at emergence was marginally significant $\left(F_{(1,34)}=\right.$ 4.1, $P=0.052)$, while temperature and the interaction term were both non-significant $\left(F_{(1,34)}<1.4, P>0.24\right)$. However, the qualitative differences in dry mass at emergence for $A n$. coluzzii were similar to those of Exp. 1 (Fig. 2d). Unlike Exp. 1, body lipid mass at emergence was significantly affected by the treatment for both species (Fig. 2f). For female An. arabiensis, lipid mass at emergence was significantly affected by temperature $\left(F_{(1,19)}=25.3, P=0.0001\right)$ but not by photoperiod or the interaction term $\left(F_{(1,19)}<0.08, P>0.8\right)$; female $A n$. arabiensis had higher amounts of lipids under both wetseason temperature treatments as compared with the two dry-season temperature treatments (Fig. 2f). By contrast, for female An. coluzzii, photoperiod $\left(F_{(1,34)}=47.4\right.$, $P<0.0001)$ and the interaction term $\left(F_{(1,34)}=22.9, P<\right.$ $0.0001)$, but not temperature alone $\left(F_{(1,34)}=2.7, P=\right.$ $0.11)$, significantly affected lipid mass at emergence. Female $A n$. coluzzii raised under the dry-dry treatment had the highest amount of lipid at emergence (Fig. 2f), similar to the trend seen in Exp. 1 (Fig. 2e). Moreover, relative lipid content was also not significantly different between treatments in An. arabiensis $\left(F_{(1,19)}<1.7, P>\right.$ $0.19)$ but significantly differed between treatments in An. coluzzii $\left(F_{(1,34)}=10.1, P<0.0001\right)$. Notably, under shorter photoperiod and lower nightly temperature relative lipid content was highest in $A n$. coluzzii (Additional file 1: Figure S2).

\section{Adult longevity}

Longevity (from adult ecolosion to death) of a total of 1473 females consisting of 676 and 797 of An. arabiensis and $A n$. coluzzii, respectively (including 74 and 81 censored mosquitoes, respectively) was measured in Exp. 1. Longevity of a total of 2041 females consisting of
392 and 1657 of An. arabiensis and An. coluzzii, respectively (with additional 84 and 229 censored mosquitoes, respectively) was measured in Exp. 2. Overall mean longevity of An. arabiensis and $A n$. coluzzii in the first and second experiments were $19.4 \mathrm{~d}$ $(\mathrm{SE}=0.39, \max =55 \mathrm{~d})$ and $20.5 \mathrm{~d}(\mathrm{SE}=0.38, \max =63$ d), $26.5 \mathrm{~d}(\mathrm{SE}=0.52, \max =59 \mathrm{~d})$, and $25.8 \mathrm{~d}(\mathrm{SE}=0.26$, $\max =64 \mathrm{~d})$, respectively.

\section{Experiment 1}

For An. arabiensis, no significant difference in female longevity was found between the three photoperiod treatments tested (Wilcoxon $\chi^{2}=0.94, d f=2, P=0.59$; Fig. $3 \mathrm{~b}$ ), with mean longevity under the wet-season photoperiod at $20.0 \mathrm{~d}(\mathrm{SE}=0.84)$, under the transition photoperiod at $19.2 \mathrm{~d}(\mathrm{SE}=0.62)$, and under the dry-season photoperiod at $19.3 \mathrm{~d}(\mathrm{SE}=0.62)$. In contrast, photoperiod significantly affected longevity of female An. coluzzii (Wilcoxon $\chi^{2}=$ 30.04, $d f=2, P<0.0001$; Fig. 3a), with dry-season mosquitoes having the highest mean longevity $(23.1 \mathrm{~d}, \mathrm{SE}=0.64)$, wet-season mosquitoes having the shortest mean longevity (18.0 d, SE $=0.60)$, and transition photoperiod mosquitoes having intermediate longevity $(20.6 \mathrm{~d}, \mathrm{SE}=0.74)$.

\section{Experiment 2}

Unlike Exp. 1, mean longevity of female An. arabiensis was significantly affected by treatment (Wilcoxon $\chi^{2}=$ $30.2, d f=3, P<0.0001)$, with higher longevity under dryseason photoperiod/wet-season temperature $(32.0 \mathrm{~d}, \mathrm{SE}$ $=1.3$ ), as compared with the wet-season photoperiod/ dry season temperature $(23.5 \mathrm{~d}, \mathrm{SE}=1.1)$, and wet-wet $(24.8 \mathrm{~d}, \mathrm{SE}=0.96)$ treatments (Fig. 3d). Notably, the drydry treatment $(27.0 \mathrm{~d}, \mathrm{SE}=0.77)$ was intermediate and statistically similar to all other treatments (after TukeyKramer multiple test adjustment: $P>0.087)$. For $A n$. coluzzii, treatment also significantly affected female longevity (Wilcoxon $\chi^{2}=85.7, d f=3, P<0.0001$; Fig. $3 c$ ). In contrast to $A n$. arabiensis, for $A n$. coluzzii the highest mean longevity was exhibited under the dry/dry treatment (30.1 d, SE $=0.68)$, which was significantly greater than all other treatments (after Tukey-Kramer multiple test adjustment: $P<0.039)$. The next highest mean longevity was achieved under dry photoperiod/wet temperature $(26.9 \mathrm{~d}, \mathrm{SE}=0.51)$, which was higher than the two wet-season photoperiod treatments, which were also not significantly different from each other (wet-dry $=24.2 \mathrm{~d}, \mathrm{SE}=0.46$ and wet-wet $=23.8 \mathrm{~d}, \mathrm{SE}=0.47$ ). Initial adult density did not affect longevity of $A n$. arabiensis $(P>0.90)$ or $A n$. coluzzii (Wilcoxon $\chi^{2}=0.5, d f=$ $1, P>0.48)$.

\section{Discussion}

The mechanisms by which anopheline mosquitoes survive the long dry season in the African Sahel is one of 

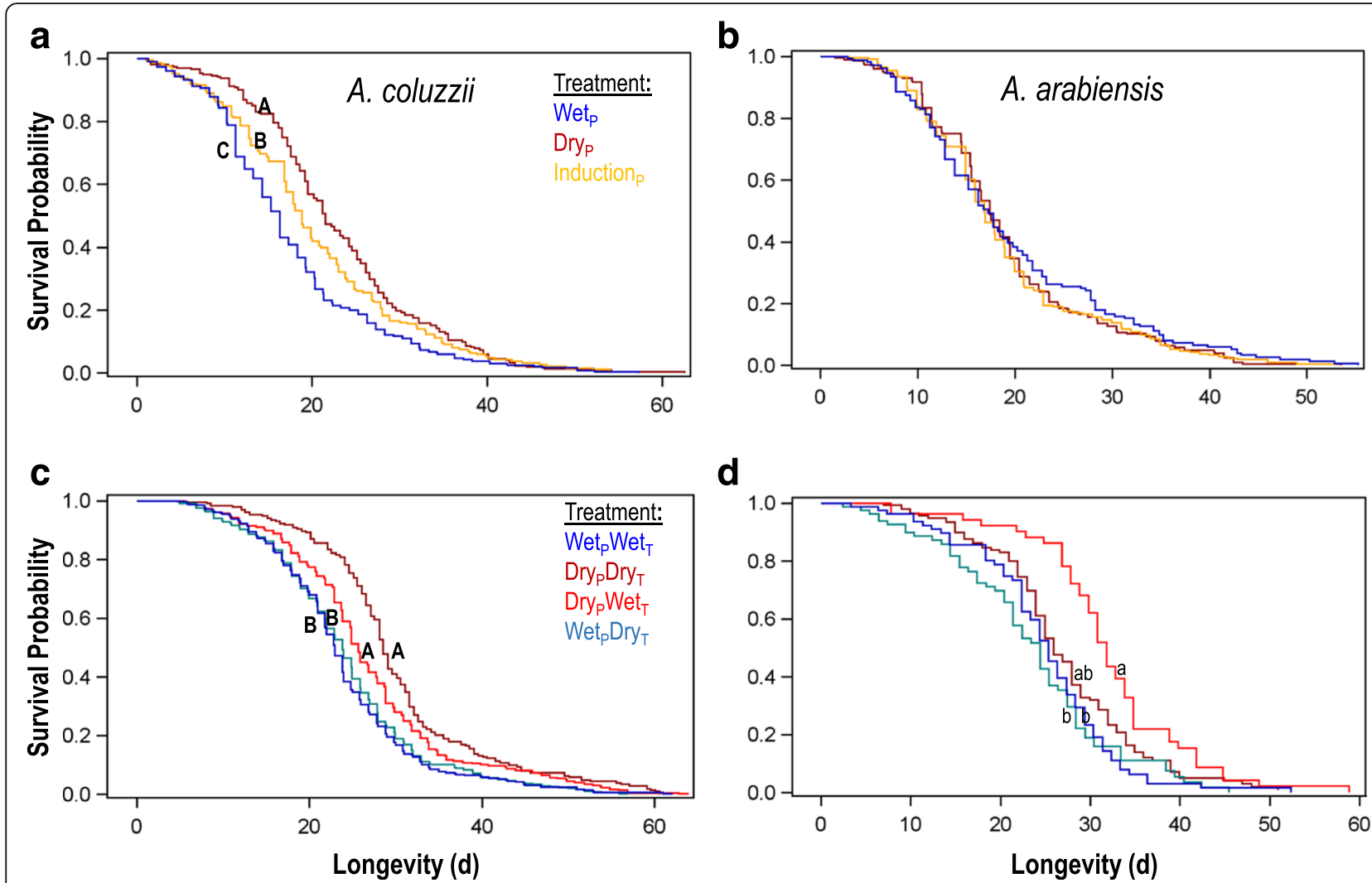

d

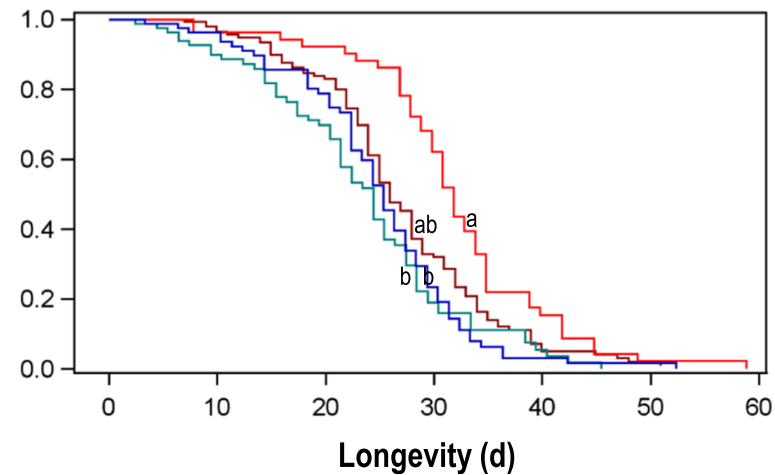

Fig. 3 Longevity of female A. coluzzii (panels $\mathbf{a}, \mathbf{c}$ ) and $A$. arabiensis (panels $\mathbf{b}, \mathbf{d}$ ) under three photoperiod treatments (Experiment 1 ; panels $\mathbf{a}$, $\mathbf{b}$ ) and four photoperiod-temperature treatment combinations (Experiment 2; panels $\mathbf{c}$, d), described in Fig. 1. Letters designate significantly different values within each species and treatment combination (log-rank test with multiple comparisons)

the longest standing questions in medical entomology [58]. Recent studies have indicated that An. coluzzii likely aestivates locally while An. gambiae and $A n$. arabiensis recolonize yearly towards the beginning of the rainy season $[8,20,25,27-30,32,33]$. Additional research continues to gather evidence testing new aspects of this hypothesis, yet, the environmental conditions which initiate aestivation and migration are poorly known for tropical mosquitoes and insect species $[6,21,34,59]$. The present study aimed to induce aestivation in An. coluzzii under laboratory conditions by manipulating photoperiod and temperature. The rationale for this approach is the importance of these environmental factors as cues for adult mosquitoes undergoing diapause [43, 60-69] and the observation that tropical insects from as low latitudes as $9^{\circ}$ use photoperiod as a cue to initiative aestivation [45]. Our experimental approach also included a comparison of the response to photoperiod and temperature between the aestivating species An. coluzzii and its nonaestivating sibling species, $A n$. arabiensis. In the first experiment, we simulated three field-relevant photoperiods: wet-season, dry-season, and wet-dry transition (all under constant temperature of $27{ }^{\circ} \mathrm{C}$ ). In the second experiment, we combined wet-season and dry-season photoperiods with temperature modulations to mimic natural field conditions during these seasons. These studies were designed to test the hypothesis that short photoperiod and lower nightly temperatures could trigger physiological changes which increase lifespan of the presumably aestivating species $A n$. coluzzii, but will not produce such responses in An. arabiensis (Table 1). The second experiment not only expanded the factors tested to include nightly lower temperatures which was found to vary sharply during the transition from the wet to the dry season [21], but also allowed assessment of the response's robustness through its repeatability. The effect of the treatments on longevity arguably provides the best measure of the response of An. coluzzii relevant to aestivation.

Our key findings demonstrated that short photoperiod, and to a lesser extent, lower nightly temperature, significantly increased longevity of An. coluzzii in both experiments (Fig. 3). The increase in longevity of An. coluzzii from wet to dry season photoperiod was modest (30.0 and $24.4 \%$, respectively) but statistically significant $(P<$ 0.001 ). Additionally, body size (wing length) increased in response to short photoperiod in both experiments 
(Fig. 2a, b), as was previously found in field studies [6, $20,27,29,30,32]$ and in accord with a previous laboratory study [34]. The larger adult size was attained despite a shorter larval developmental time (trend in both experiments, but significantly so only in Exp. 1; Fig. 1). Body mass of $A n$. coluzzii followed body size (trend in both experiments, but significantly only in Exp. 1). Total lipid mass at emergence was elevated under dry season conditions, but significantly so only in Exp. 2 (Fig. 3). Triacylglyceride lipids are a common form of energy storage during diapause in insects, likely due the relatively low hydration state and high metabolic water yield of these molecules [62]. Thus, reduced pre-adult development time (Fig. 1a), increased body size (Fig. 2a, b), increased body mass (Fig. 2c) and increased lipid mass (Fig. 2f), as well as increased adult longevity (Fig. 3a, c) in response to changes between wet-season and dryseason photoperiod/temperature conditions are all consistent with a coordinated aestivation "syndrome". These coordinated changes also suggest trade-offs elsewhere in the life-cycle under dry season conditions, which are likely manifest as reduced reproductive output, consistent with the lack of dry season reproduction in nature $[21,32]$. These results suggest that An. coluzzii has entered a diapause initiation phase in our experiments, at least partly. Nonetheless, these environmental changes alone failed to manifest a bona fide aestivating adult recognized by a longevity greater than 3 months, raising the question of what (if any) additional conditions must be met if aestivation is to be manifested?

Under the same conditions, An. arabiensis exhibited no consistent increase of longevity (Fig. 3). Specifically, longevity of $A n$. arabiensis under dry season conditions was not significantly longer than any other treatment in both experiments (Fig. 2). Moreover, its body size as well as body mass decreased (Fig. 2), in contrast to the response of $A n$. coluzzii. The differing responses in this experiment of An. coluzzii and An. arabiensis to photoperiodic conditions characteristic of wet and dry seasons in the Sahel further supports our hypothesis of alternative life-history responses to dry seasons in nature. The prediction that An. arabiensis uses photoperiod to initiate long-distance migration may be more directly tested using assays of flight aptitude rather than longevity. However, the species-specific responses demonstrated in this study underscore the capacity of tropical anophelines to detect subtle environmental cues on the one hand and the role these seasonal changes play as token stimuli for $A n$. coluzzii in induction of aestivation, on the other. In Exp. 2, lower nightly temperature did not increased the response of either species in terms of larval developmental time, body size, and mass for $A n$. coluzzii. In $A n$. arabiensis, lower nightly temperatures yielded no difference in longevity with respect to all other treatments, indicating no response to temperature. However, under short photoperiod, lower nightly temperature led to an increase in mean longevity for $A n$. coluzzii. The effect of lower nightly temperatures was not detected under long photoperiod (Fig. 3), suggesting that this effect was not mediated by the lower nightly temperature alone. Additional regimes of temperature and photoperiod might extend longevity further.

In the temperate zone, photoperiod changes provide the primary cue used by insects and mosquitoes in particular to induce diapause and temperature may also play a role, but typically of lesser importance [40, 43, 45, 46]. In mosquitoes, including Culiseta inornata, the only species for which a laboratory model of aestivation is available, photoperiod change was sufficient to induce aestivation [63-65, 68, 69]. Furthermore, previous laboratory studies have suggested that short photoperiod results in longer longevity and large body size in (presumably) non-diapausing $A n$. quadrimaculatus and $A n$. crucians mosquitoes that originated from north Florida [70-72]; yet, the authors could not offer an explanation or an adaptive benefit for these responses. Because the range of both these species includes expansive temperate regions where overwintering diapause must occurs, it is difficult to rule out that the observed responses were indeed linked to diapause. Further, even under mild winter conditions, diapause may be selected for, as is the case of Drosophila melanogaster [73]. Additional studies are needed to clarify whether short photoperiod induce extended longevity and larger body size in non-diapausing mosquitoes, however, given the extensive body of evidence connecting these responses to diapause, it seems prudent to connect responses to photoperiod with diapause (aestivation). Accordingly, the extended longevity and larger body size at emergence despite a shorter larval developmental time of $A n$. coluzzii in response to $1 \mathrm{~h}$ changes in photoperiod are difficult to explain without reference to aestivation.

The seemingly effortless success of early studies on laboratory simulation of aestivation of presumably $A n$. coluzzii in Burkina Faso [18] and An. arabiensis in Sudan [6] has met with serious challenges for replication. Sadly, the previous authors have provided insufficient details about their experimental procedures. Whether their success in maintaining females of these species between three and 6 months during the dry season was dependent on the particular population, time of the year, or a "secret ingredient" of their procedure, have remained elusive as this and similar investigations have shown $[59,74]$. It is possible that more extreme photoperiod and temperature conditions integrated with changes in $\mathrm{RH}$ are necessary to produce the diapause initiation phase in full. Additionally, the conditions required for diapause maintenance remain less known. 
Potentially these include, total darkness, lower temperature, dietary changes, and even changes in gas composition if the shelters used by the species are deep underground. For example, if aestivating mosquitoes shelter in deep termite mounds, they might be exposed not only to mild temperatures and total darkness, but also to unique volatiles. Could such termite nests be under the insectaries of Holstein in Burkina Faso [18] and Omar and Cloudsley-Thompson in the Sudan [6]?

\section{Conclusions}

We compared the responses of An. coluzzii and An. arabiensis to changes in photoperiod and temperature and specifically aimed to induce aestivation in An. coluzzii under shorter photophase and lower nightly temperature, typical of the early dry season. Under dry season conditions, longevity, body size, and total lipids of An. coluzzii increased despite a shorter larval developmental time, consistent with a coordinated aestivation "syndrome". Under the same conditions, longevity of $A n$. arabiensis did not increase and its body size decreased. These results provide evidence for a differential response to photoperiod in these species and that An. coluzzii has entered a diapause initiation phase in our experiments, at least partly. Nonetheless, these environmental changes alone failed to manifest a bona fide aestivating adult recognized by a longevity greater than 3 months, raising the question of what (if any) additional conditions must be met if aestivation is to be manifested?

\section{Additional files}

Additional file 1: Figure S1. Cage design of Experiment 2, with plastic "shelter" in one corner of the cage. Figure S2. The relative lipid content of female An. arabiensis (white circles) and An. coluzzii (black squares) under three photoperiod treatments (Experiment 1; panel a) and four photoperiod-temperature treatment combinations (Experiment 2; panel b). Least square means $\pm 95 \% \mathrm{Cl}$ are given for each trait and significantly different values within each species are designated with letters. The grey dotted line denotes the critical comparison between wet-season and dry-season An. coluzzii in each experiment. (ZIP $3439 \mathrm{~kb}$ )

\section{Abbreviations}

ANOVA: Analysis of variance; Cl: Confidence interval; d: Day; L:D: Light:dark; LMVR: Laboratory of Malaria and Vector Research $(\mathrm{NIH})$; RH: Relative humidity; SE: Standard deviation of the mean

\section{Acknowledgements}

We thank Drs Alpha S Yaro, Adama Dao, and Richard Sakai for facilitating collection of wild-caught mosquitoes to establish the colonies used in this study and A. Haile and A. Molina-Cruz for assistance with mouse-feeding under NIH animal care Protocol ID: LMVR105, Mr André Laughinghouse and Kevin Lee for logistical support, and Drs José MC Ribeiro, Roy Faiman, and Ben Krajacich for comments on previous versions of this manuscript. This research was supported by the Intramural Research Programme of the $\mathrm{NIH}$ NIAID.

\section{Funding}

This study was supported by the Division of Intramural Research, National Institute of Allergy and Infectious Diseases, National Institutes of Health.

\section{Availability of data and materials}

The datasets used during and/or analyzed during the current study are available from the corresponding author upon request.

\section{Authors' contributions}

DLH conceived and designed the study, carried out the experiments, analyzed and interpreted the results and wrote the manuscript. MA carried out the experiments and recorded the results. PA designed the study, interpreted the results, and helped in writing the MS. TL conceived and designed the study, analyzed and interpreted the results and wrote the MS. All authors read and approved the final manuscript.

Ethics approval and consent to participate

This study was carried out in accordance with the recommendations in the Guide for the Care and Use of Laboratory Animals of the National Institutes of Health. All animal procedures were approved by the National Institutes of Health Animal Care and Use Committee (ACUC, Protocol ID: LMVR105). No human participants, human data or human tissue were used.

\section{Consent for publication}

Not applicable.

\section{Competing interests}

The authors declare that they have no competing interests.

\section{Publisher's Note}

Springer Nature remains neutral with regard to jurisdictional claims in published maps and institutional affiliations.

\section{Author details}

'Laboratory of Malaria and Vector Research, National Institute of Allergy and Infectious Diseases, National Institutes of Health, Rockville, MD, USA.

${ }^{2}$ Department of Biology, Georgetown University, Washington, DC, USA.

Received: 3 March 2017 Accepted: 26 November 2017

Published online: 27 December 2017

\section{References}

1. WHO. World malaria report 2014. Geneva: World Health Organization; 2014.

2. Coetzee M, Craig M, le Sueur D. Distribution of African malaria mosquitoes belonging to the Anopheles gambiae complex. Parasitol Today. 2000;16:74-7.

3. Lindsay SW, Parson L, Thomas CJ. Mapping the ranges and relative abundance of the two principal African malaria vectors, Anopheles gambiae sensu stricto and An. arabiensis, using climate data. Proc R Soc Lond B Biol Sci. 1998;265:847-54

4. White GB. Anopheles gambiae complex and disease transmission in Africa. Trans Roy Soc Trop Med Hyg. 1974;68:278-98.

5. Bayoh MN, Thomas CJ, Lindsay SW. Mapping distributions of chromosomal forms of Anopheles gambiae in West Africa using climate data. Med Vet Entomol. 2001;15:267-74.

6. Omer SM, Cloudsley-Thompson JL. Dry season biology of Anopheles gambiae Giles in the Sudan. Nature. 1968:217:879-80.

7. Simard F, Lehmann T, Lemasson JJ, Diatta M, Fontenille D. Persistence of Anopheles arabiensis during the severe dry season conditions in Senegal: an indirect approach using microsatellite loci. Insect Mol Biol. 2000;9:467-79.

8. Dao A, Yaro AS, Diallo M, Timbine S, Huestis DL, Kassogue Y, et al. Signatures of aestivation and migration in Sahelian malaria mosquito populations. Nature. 2014;516:387-90

9. Hastenrath S, Polzin D. Variability of circulation and Sahel rainfall in the twentieth century. Int J Climatol. 2014;34:1693-8.

10. Tarhule A, Zume JT, Grijsen J, Talbi-Jordan A, Guero A, Dessouassi RY, et al. Exploring temporal hydroclimatic variability in the Niger Basin (1901-2006) using observed and gridded data. Int J Climatol. 2015;35:520-39.

11. Lehmann T, Diabate A. The molecular forms of Anopheles gambiae: a phenotypic perspective. Inf Genet Evol. 2008:8:737-46.

12. Ameneshewa B, Service MW. The relationship between female body size and survival rate of the malaria vector Anopheles arabiensis in Ethiopia. Med Vet Entomol. 1996;10:170-2.

13. Costantini C, Li SG, Della Torre A, Sagnon N, Coluzzi M, Taylor CE. Density, survival and dispersal of Anopheles gambiae complex mosquitoes in a west African Sudan savanna village. Med Vet Entomol. 1996;10:203-19. 
14. Dao A, Kassogue Y, Adamou A, Diallo M, Yaro AS, Traore SF, Lehmann T. Reproduction-longevity trade-off in Anopheles gambiae (Diptera: Culicidae) J Med Entomol. 2010;47:769-77.

15. Artis ML, Huestis $\mathrm{DL}$, Lehmann T. The effects of oviposition-site deprivation on longevity and blood-feeding rate in Anopheles gambiae. Parasit Vectors. 2014;7:163.

16. Benedict MQ, Sandve SR, Wilkins EE, Roberts JM. Relationship of larval desiccation to Anopheles gambiae Giles and An. arabiensis Patton survival. J Vector Ecol. 2010;35:116-23.

17. Beier JC, Copeland RS, Oyaro C, Masinya A, Odago WO, Odour S, et al. Anopheles gambiae complex egg stage survival in dry soil from larval development sites in western Kenya. J Am Mosq Control Assoc. 1990;6:105-9.

18. Holstein MH. Biology of Anopheles gambiae - research in French West Africa. Geneva: World Health Organization; 1954

19. Omer SM, Cloudsley-Thompson JL. Survival of female Anopheles gambiae Giles through a 9-month dry season in Sudan. Bull World Health Organ. 1970:42:319-30

20. Lehmann T, Dao A, Yaro AS, Adamou A, Kassogue Y, Diallo M, et al. Aestivation of the African malaria mosquito, Anopheles gambiae in the Sahel. American. J Trop Med Hyg. 2010;83:601-6.

21. Huestis DL, Lehmann T. Ecophysiology of Anopheles gambiae s.l. persistence in the Sahel. Infect Genet Evol. 2014;28:648-61.

22. Donnelly MJ, Simard F, Lehmann T. Evolutionary studies of malaria vectors. Trends Parasitol. 2002;18:75-80

23. Charlwood JD, Vij R, Billingsley PF. Dry season refugia of malariatransmitting mosquitoes in a dry savannah zone of east Africa. Am J Trop Med Hyg. 2000;62:726-32.

24. Coetzee M, Hunt RH, Wilkerson R, Della Torre A, Coulibaly MB, Besansky NJ. Anopheles coluzzii and Anopheles amharicus, new members of the Anopheles gambiae complex. Zootaxa. 2013;3619:246-74.

25. Lehmann T, Dao A, Yaro AS, Diallo M, Timbine S, Huestis DL, et al. Seasonal variation in spatial distributions of Anopheles gambiae in a Sahelian village: evidence for aestivation. J Med Entomol. 2014;51:27-38.

26. Mamai W, Mouline K, Parvy JP, Le Lannic J, Dabire KR, Ouedraogo GA, et al. Morphological changes in the spiracles of Anopheles gambiae s.l. (Diptera) as a response to the dry season conditions in Burkina Faso (West Africa). Parasit Vectors. 2016;9:11

27. Mamai W, Simard F, Couret D, Ouedraogo GA, Renault D, Dabire KR, Mouline K. Monitoring dry season persistence of Anopheles gambiae s.l. populations in a contained semi-field system in southwestern Burkina Faso, West Africa. J Med Entomol. 2016;53:130-8.

28. Adamou A, Dao A, Timbine S, Kassogue Y, Yaro AS, Diallo M, et al. The contribution of aestivating mosquitoes to the persistence of Anopheles gambiae in the Sahel. Malar J. 2011;10:151.

29. Arcaz A, Huestis DL, Dao A, Yaro AS, Diallo M, Andersen J, et al. Desiccation tolerance in Anopheles coluzzii: the effects of spiracle size and cuticular hydrocarbons. J Exp Biol. 2016; in press

30. Huestis DL, Yaro AS, Traore Al, Dieter KL, Nwagbara Jl, Bowie AC, et al. Seasonal variation in metabolic rate, flight activity and body size of Anopheles gambiae in the Sahel. J Exp Biol. 2012;215:2013-21.

31. Mamai W, Mouline K, Blais C, Larvor V, Dabire KR, Ouedraogo GA, et al. Metabolomic and ecdysteroid variations in Anopheles gambiae s.l. mosquitoes exposed to the stressful conditions of the dry season in Burkina Faso, West Africa. Physiol Biochem Zool. 2014;87:486-97.

32. Yaro AS, Traore Al, Huestis DL, Adamou A, Timbine S, Kassogue Y, et al. Dry season reproductive depression of Anopheles gambiae in the Sahel. J Insect Physiol. 2012;58:1050-9.

33. Hidalgo K, Mouline K, Mamai W, Foucreau N, Dabire KR, Bouchereau A, Simard F, Renault D. Novel insights into the metabolic and biochemical underpinnings assisting dry-season survival in female malaria mosquitoes of the Anopheles gambiae complex. J Insect Physiol. 2014;70:102-16.

34. Wagoner KM, Lehmann T, Huestis DL, Ehrmann BM, Cech NB, Wasserberg G. Identification of morphological and chemical markers of dry- and wetseason conditions in female Anopheles gambiae mosquitoes. Parasit Vectors. 2014;7:294.

35. Tombes AS. Respiratory and compositional study on the aestivating insect, Hypera postica (Gyll) (Curculionidae). J Insect Physiol. 1964;10:997-1003.

36. Masaki S. Summer diapause. Annu Rev Entomol. 1980;25:1-25.

37. Kostal V, Hodek I. Photoperiodism and control of summer diapause in the Mediterranean tiger moth Cymbalophora pudica. J Insect Physiol. 1997;43: 767-77.
38. Held C, Spieth HR. First evidence of pupal summer diapause in Pieris brassicae L.: the evolution of local adaptedness. J Insect Physiol. 1999;45: 587-98.

39. Liu ZD, Gong PY, Wu KJ, Sun JH, Li DM. A true summer diapause induced by high temperatures in the cotton bollworm, Helicoverpa armigera (Lepidoptera: Noctuidae). J Insect Physiol. 2006;52:1012-20.

40. Danilevskii AS. Photoperiodism and seasonal development of insects. Edinburgh and London: Oliver \& Boyd; 1965.

41. Armbruster PA. Photoperiodic diapause and the establishment of Aedes albopictus (Diptera: Culicidae) in North America. J Med Entomol. 2016;53: 1013-23.

42. Urbanski J, Mogi M, O'Donnell D, DeCotiis M, Toma T, Armbruster P. Rapid adaptive evolution of photoperiodic response during invasion and range expansion across a climatic gradient. Am Nat. 2012;179:490-500.

43. Denlinger DL, Armbruster PA. Mosquito diapause. Annu Rev Entomol. 2014; 59:73-93.

44. Denlinger DL, Armbruster PA. Molecular physiology of mosquito diapause Adv Insect Physiol. 2016;51:329-61.

45. Denlinger DL. Dormancy in tropical insects. Annu Rev Entomol. 1986;31: 239-64.

46. Bradshaw WE, Holzapfel CM. Evolution of animal photoperiodism. Annu Rev Ecol Evol S. 2007;38:1-25

47. Wolda $\mathrm{H}$, Denlinger DL. Diapause in a large aggregation of a tropical beetle. Ecol Entomol. 1984;9:217-30

48. Goymann W, Helm B, Jensen W, Schwabl I, Moore IT. A tropical bird can use the equatorial change in sunrise and sunset times to synchronize its circannual clock. Proc Biol Sci. 2012;279:3527-34.

49. Hau M, Wikelski M, Wingfield JC. A neotropical forest bird can measure the slight changes in tropical photoperiod. Proc Roy Soc B-Biol Sci. 1998:265:89-95

50. Monge JP, Lenga A, Huignard J. Induction of reproductive diapause in Bruchidius atrolineatus during the dry season in a Sahelian zone. Entomol Exp Applicat. 1989;53:95-104

51. Huignard J, Monge JP, Germain JF. Influence of thermoperiodic variations on the induction of the reproductive diapause of Bruchidius atrolineatus (Pic) (Coleoptera, Bruchidae). In: Tonner M, Soldan T, Bennetova B, editors. Regulation of insect reproduction IV. Praha: Academia Praha; 1989, pp. 197-207.

52. Denlinger DL. Why study diapause. Entomol Res. 2008:38:1-9.

53. Fanello C, Santolamazza F, Della Torre A. Simultaneous identification of species and molecular forms of the Anopheles gambiae complex by PCRRFLP. Med Vet Entomol. 2002;16:461-4.

54. Huestis DL, Yaro AS, Traore Al, Adamou A, Kassogue Y, Diallo M, et al. Variation in metabolic rate of Anopheles gambiae and $A$. arabiensis in a Sahelian village. J Exp Biol. 2011;214:2345-53.

55. Van Handel E. Rapid determination of total lipids in mosquitoes. J Am Mosq Control Assoc. 1985;1:302-4.

56. Tauber MJ, Tauber CA, Masaki S. Seasonal adaptations of insects. New York: Oxford University Press; 1986

57. SAS Institute. Inc. SAS for windows version 9.3. 1st ed. Cary: SAS Institute; 2011.

58. Gillies MT, De Meillon B. The Anophelinae of Africa south of the Sahara. 2nd ed. Johannesburg: South African Institute for Medical Research; 1968.

59. Ramsdale CD, Fontaine RE. Ecological investigations of Anopheles gambiae and Anopheles funestus II. Dry season studies with colony-reared A. gambiae species B, Kaduna Nigeria. WHO/NBC/70249 1970(WHO/MAL/70.736). 1970; 1-8. (WHO/MAL/70.736).

60. Urbanski JM, Benoit JB, Michaud MR, Denlinger DL, Armbruster P. The molecular physiology of increased egg desiccation resistance during diapause in the invasive mosquito, Aedes albopictus. Proc Biol Sci. 2010;277: 2683-92.

61. Robich RM, Denlinger DL. Diapause in the mosquito Culex pipiens evokes a metabolic switch from blood feeding to sugar gluttony. Proc Natl Acad Sci USA. 2005;102:15912-7.

62. Hahn DA, Denlinger DL. Energetics of insect diapause. Annu Rev Entomol. 2011;56:103-21.

63. Barnard DR, Mulla MS. Effects of photoperiod and temperature on bloodfeeding oogensis, and fat body development in the mosquito, Culiseta inornata. J Insect Physiology. 1977;23:1261-6.

64. Buth JL, Brust RA, Ellis RA. Development time, oviposition activity and onset of diapause in Culex tarsalis, Culex restuans and Culiseta inornata in southern Manitoba. J Am Mosq Control Assoc. 1990;6:55-63. 
65. Hudson JE. Indcution of diapause in female mosquitoes, Culiseta inornata by a decrease in daylength. J Insect Physiol. 1977;23:1377-82.

66. Eldridge BF. The effect of temperature and photoperiod on blood-feeding and ovarian development in mosquitoes of the Culex pipiens complex. Am J Trop Med Hyg. 1968;17:133-40.

67. Vinogradova EB. Diapause in aquatic insects, with emphasis on mosquitoes. In: Alekseev VR, De Stasio B, Gilbert JJ, editors. Diapause in aquatic invertebrates. London: Springer; 2007, pp. 83-113.

68. Reisen WK, Meyer RP, Milby MM. Studies on the seasonality of Culiseta inornata in Kern County, California. J Am Mosq Control Assoc. 1989;5: 183-95.

69. Barnard DR, Mulla MS. The ecology of Culiseta inornata in the Colorado Desert of California: seasonal abundance, gonotrophic status, and oviparity of adult mosquitoes. Ann Entomol Soc Am. 1978;71:397-401.

70. Lanciani CA. Photoperiod and the relationship between wing length and body-weight in Anopheles quadrimaculatus. J Am Mosq Control Assoc. 1992; 8:297-300.

71. Lanciani CA. Photoperiod and longevity in Anopheles crucians. J Am Mosql Control Assoc. 1993;9:308-12.

72. Lanciani CA, Anderson JF. Effect of photoperiod on longevity and metabolic-rate in Anopheles quadrimaculatus. J Am Mosq Control Assoc. 1993:9:158-63.

73. Saunders DS, Henrich VC, Gilbert LI. Induction of diapause in Drosophila melanogaster - photoperiodic regulation and the impact of arrhythmic clock mutations on rime measurement. Proc Natl Acad Sci USA. 1989;86:3748-52.

74. Warburg A, Toure YT. Estivation of Anopheles gambiae: potential habitats and physiology. AID Grant Report 2002, Grant Number: TAMOU-97-C17-002.

\section{Submit your next manuscript to BioMed Central} and we will help you at every step:

- We accept pre-submission inquiries

- Our selector tool helps you to find the most relevant journal

- We provide round the clock customer support

- Convenient online submission

- Thorough peer review

- Inclusion in PubMed and all major indexing services

- Maximum visibility for your research

Submit your manuscript at www.biomedcentral.com/submit 